\title{
COMPARATIVE STUDY OF ROPIVACAINE ALONE VERSUS ROPIVACAINE WITH DEXMEDETOMIDINE IN SUPRACLAVICULAR BRACHIAL PLEXUS BLOCK
}

\author{
J. Ramana Prasad ${ }^{1}$, Farooq Basha $S^{2}$ \\ ${ }^{1}$ Associate Professor, Department of Anaesthesiology, ACSR Government Medical College, Nellore. \\ ${ }^{2}$ Assistant Professor, Department of Anaesthesia, ACSR Government Medical College, Nellore.
}

\begin{abstract}
This is a randomized controlled study is to compare the sensory and motor effects after injection of ropivacaine $0.75 \%$ plain and ropivacaine $0.75 \%$ with dexmedetomidine as adjunct, used for supraclavicular brachial plexus block in 60 ASA grade I \&II. Ropivacaine New long acting drug similar in structure, pharmacology and pharmacokinetics like bupivacaine but lower toxicity pure s-enantiomer it shows more sensory blockade Lower cardiac toxicity. Dexmedetomidine, an alpha-2 adrenoreceptor agonist was introduced into clinical practice as a short term sedative $(<24 \mathrm{hrs})$ and has been targeted for use in the perioperative period. Dexmedetomidine decreases sympathetic tone with attenuation of neuroendocrine and hemodynamic responses to anaesthesia and surgery, reduces anaesthetic requirement, causes sedation and analgesia. The current study is designed to test the hypothesis that dexmedetomidine when added as an adjuvant to local anaesthetic in supraclavicular brachial plexus block prolongs the duration of sensory and motor block. We assessed time of onset, duration of sensory blockade and also time of onset \& duration of motor blockade.
\end{abstract}

\section{KEYWORDS}

Brachial Plexus, Ropivacaine, Dexmedetomidine, Sensory Blockade and Motor Blockade.

HOW TO CITE THIS ARTICLE: Prasad JR, Farooq Basha S. Comparative study of ropivacaine alone versus ropivacaine with dexmedetomidine in supraclavicular brachial plexus block. J Evolution Med Dent Sci 2016;5(3):233-240, DOI: 10.14260/jemds/2016/50

\section{INTRODUCTION}

Pain is "An unpleasant sensory or emotional experience associated with actual or potential tissue damage or described in terms of such damage." It is an unpleasant effect associated with significant psychological and physiological changes during surgery and post-operative period.

The ability to modulate pain in the nerve path way forms the basis of peripheral neural block has emerged as a comprehensive anesthetic care from standalone anesthesia to post-operative pain management. Brachial plexus block works as an alternative to general anesthesia in upper limb surgeries. Supraclavicular brachial plexus approach is preferred for its rapid onset, reliable anesthesia and as a safe technique for any surgery in the upper extremity that does not involve the shoulder.

Various local anesthetics have been used to produce brachial plexus block. Ropivacaine, a long-acting amide local anesthetic related structurally to bupivacaine, has been used for supraclavicular block in upper limb surgery. It provides pain relief with less motor blockade and is less cardio toxic than bupivacaine, which makes it a more suitable agent for supraclavicular brachial plexus block.

Hickey et al. ${ }^{1}$ compared the effectiveness of $0.5 \%$ ropivacaine and $0.5 \%$ bupivacaine for brachial plexus block and found that ropivacaine $0.5 \%$ and bupivacaine $0.5 \%$ appeared equally effective in providing brachial plexus anesthesia.

Financial or Other, Competing Interest: None.

Submission 01-12-2015, Peer Review 02-12-2015,

Acceptance 07-12-2015, Published 11-01-2016.

Corresponding Author:

Dr. J. Ramana Prasad,

26-17-2, Chaitanya Nagar,

Gajuwaka,

Vizag-530026.

E-mail: jammala.rp50@gmail.com

DOI:10.14260/jemds/2016/50
A variety of adjuvant have been used with local anesthetics to increase the efficacy and reduce the incidence of adverse efforts, those studied for brachial plexus blockade include opioid and non-opioid agents.

In non-opioids Dexmedetomidine has been already used for intravenous regional anesthesia (Bier's block). Dexmedetomidine has shown greater affinity as an alfa-2 adrenoreceptor agonist than clonidine. The effect of Dexmedetomidine when added to lidocaine for intravenous regional anesthesia, demonstrate that addition of $1 \mathrm{mcg} / \mathrm{kg}$ dexmedetomidine to lidocaine improves quality of anaesthesia and intraoperative as well postoperative analgesia without causing side effects.

Dexmedetomidine, an alpha-2 adrenoreceptor agonist was introduced into clinical practice as a short term sedative $(<24 \mathrm{hrs})$ and has been targeted for use in the perioperative period.

Dexmedetomidine has not been associated with respiratory depression, despite frequently profound levels of sedation. It decreases sympathetic tone with attenuation of neuroendocrine and hemodynamic responses to anaesthesia and surgery, reduces anaesthetic requirement, causes sedation and analgesia. Because of arousable sedation, lack of respiratory depression and analgesia sparing effect, dexmedetomidine might prove useful in postoperative period for patient undergoing surgical procedures that are associated with significant pain.

We attempt to compare the effectiveness of ropivacaine alone and its combination with dexmedetomidine in brachial plexus block through supraclavicular route.

As per the references.2,3,4 the quality and duration of analgesia improved when dexmedetomidine is added to ropivacaine.

\section{MATERIALS AND METHODS}

The present study "Comparative study of ropivacaine alone versus ropivacaine with dexmedetomidine in supraclavicular 
brachial plexus block" was carried out on patients undergoing elective upper limb surgery at ACSR GMC, Nellore, in the Department of Anaesthesiology during the period from August 2015 to November 2015.

The study was carried out to compare hemodynamic, sedative, sensory and motor effects of Ropivacaine alone and Ropivacaine along with Dexmedetomidine in Supraclavicular Brachial Block in upper limb surgery.

The study included total 60 patients belonging to ASA grade I and II of either sex with age between 20-59 years posted for various elective upper limb surgery. Sample size was decided in consultation with a statistician.

\section{Sample Size}

After observing results of various similar studies, it was considered that a clinically significant benefit of using dexmedetomidine would be a prolongation in sensory block duration of $15 \%$ (Minimum) compared with the control group.

\section{Group-R: Ropivacaine alone}

Patients of this group received injection Ropivacaine $(0.75 \%)$ 20 milliliter +1 milliliter normal saline.

\section{Group-RD: Ropivacaine with Dexmedetomidine}

Patients of this group received injection Ropivacaine (0.75\%)

20 milliliter + Dexmedetomidine 25 microgram diluted in 1

$\mathrm{mL}$ normal saline.

Pre-anaesthetic evaluation was done on the evening before surgery.

\section{Study Method}

All patients included in the study were premeditated with tablet alprazolam $0.5 \mathrm{mg}$ and ranitidine $150 \mathrm{mg}$ orally at night. Nil oral $6 \mathrm{hrs}$. Prior to surgery. Monitoring of the patients was done as per ASA guidelines ECG, NIBP, SPO2 were recorded.

\section{PROCEDURE}

Brachial plexus block was performed by supraclavicular approach (Classical technique) with patient placed in supine position, with the head turned away from the side to be blocked. The arm to anaesthetized was adducted and the hand was extended alongside toward the ipsilateral knee as far as possible. The midpoint of clavicle was identified and marked. The point of entry was the lateral border of anterior scalene muscle (Approximately $1.5-2 \mathrm{~cm}$ posterior to the midpoint of the clavicle) at the midpoint of the clavicle which was also marked. Palpation of subclavian artery at this point confirms the landmark. Group R received $20 \mathrm{ml}$ of $0.75 \%$ Ropivacaine + $1 \mathrm{ml}$ of NS and Group RD received $20 \mathrm{ml}$ of $0.75 \%$ Ropivacaine + Dexmedetomidine 25 microgram diluted in 1 milliliter normal saline.

After appropriate preparation and injection of a skin wheel, $22 \mathrm{G}$ needle was inserted at the point of entry above the midpoint of clavicle in the Backward-Inward-Downward (BID) direction. Although, the direction of needle was towards the first rib, it was not always necessary to touch the rib. Paresthesia in the forearm or hand was elicited. After negative aspiration for air or blood appropriate drugs were injected.

Sensory and motor block along with monitoring of vitals was determined every 5 minutes in first 30 minutes and then every 15 minutes during $1^{\text {st }}$ hour followed by every second hourly during 24 hours. Any hypersensitivity reaction for the drugs, evidence of pneumothorax, and other adverse events were also monitored. To evaluate duration of sensory block and motor block, patients were asked to inform the time when initial discomfort as a sensation of pain began and also the time when full power returned to the shoulder.

In the post-operative period, when the patient complained of pain at the operative site, Injection Diclofenac $75 \mathrm{mg} \mathrm{I} / \mathrm{M}$ was given. Patients were followed up for $24 \mathrm{hrs}$. for any side effects.

\section{DEFINITIONS OF STUDY PARAMETERS Onset of Sensory Blockade}

Sensory block was assessed as loss of pinprick sensation using the blunt needle. Dermatomes C5 to T1 were assessed. Onset time is the time from the completion of injection of study drug till the loss of pinprick sensation completely.

\section{Onset of Motor Blockade}

Onset time of motor blockade is defined as the time from the completion of injection of study drug to paralysis of the upper limb.

\section{Duration of Sensory Blockade}

Duration of sensory blockade is the time from the onset of sensory blockade to till the patients complain of pain at the site of surgery.

Rescue analgesia was given after that only.

\section{Duration of Motor Blockade}

Duration of motor blockade is the time from the onset of motor blockade to complete recovery of motor power.

Sensory block was determined by the response to pin prick method using a Visual Analogue Scale (VAS)

0 - no pain.

2 - Mild pain.

5 - Moderate pain.

8 - Severe pain.

10 - Unbearable pain.

Patients were explained about the 10-point Visual Analogue Scale (VAS) with which the severity of postoperative pain was determined: 0 corresponding to "no pain" and 10 corresponding to "worst imaginable pain."

Assessment of motor blockade was done by Bromage three point score:

0 - Normal motor function with full flexion and extension of elbow, wrist and fingers.

1 - Decrease motor strength with ability to move fingers and/or wrist only.

2 - Complete motor blockade with inability to move fingers.

\section{Assessment of sedation was done by Ramsay Sedation} Scale

1. Patient is anxious and agitated or restless, or both

2. Patient is cooperative, oriented and tranquil

3. Patient responds to commands only

4. Patient exhibits brisk response to light glabellar tap or loud auditory stimulus

5. Patient exhibits a sluggish response to light glabellar tap or loud auditory stimulus

6. Patient exhibits no response to light glabellar tap or loud auditory stimulus

\section{Management of Unsuccessful/Partial Block}

In the circumstance of inadequate or patchy action of the block, the block was supplemented with general anesthesia. Such cases were excluded from the study. 
If in case surgery would have been unduly prolonged and the effect of the block wore off, analgesia would have been given in the form of intravenous Fentanyl $1 \mathrm{mcg} / \mathrm{kg}$ and infusion of Propofol $50-100 \mathrm{mcg} / \mathrm{kg} / \mathrm{min}$. These cases are not included in the study.

\section{Management of Side Effects}

Nausea and vomiting were managed by intravenous Ondansetron injection.

Hypotension is defined as mean arterial pressure less than $30 \%$ of the baseline and was corrected by Inj. Mephentermine $6 \mathrm{mg}$ IV and Fluids.

Bradycardia were managed by Inj. Atropine $0.6 \mathrm{mg}$ IV.

Haemodynamic parameters were recorded at 0 $5,10,15,20,25,30,45$ minutes, $1^{\text {st }} \mathrm{hr}, 2^{\text {nd }} \mathrm{hr}$ and thereafter every second hourly till $24 \mathrm{hrs}$.

Postoperatively, all patients received routine analgesic intramuscular injection Diclofenac $75 \mathrm{mg}$ when they started feeling pain (VAS>3). Time for first dose of rescue analgesic in postoperative period and total rescue analgesic requirement in 24 hours were recorded. The maximum pain scores and Ramsay sedation score at different time intervals (At $0,5,10,15,20,25,30,45$ minutes, $1^{\text {st }} \mathrm{hr}, 2^{\text {nd }} \mathrm{hr}$ and thereafter every second hourly till $24 \mathrm{hrs}$ in postoperative period) for each patient were recorded.

Incidences of nausea and vomiting, respiratory depression and sedation were noted. All the parameters were recorded as per the proforma and subjected to statistical analysis.

\section{OBSERVATION AND RESULTS}

Our study was conducted on 60 patients who were randomly allocated into group-R and group-RD consisting of 30 patients each.

\begin{tabular}{|c|c|c|c|}
\hline \multirow{3}{*}{$\begin{array}{c}\text { Onset of Sensory } \\
\text { block } \\
\text { (In Min) }\end{array}$} & Group R & Group RD & \multirow[b]{2}{*}{ P Value } \\
\hline & Mean \pm SD & Mean \pm SD & \\
\hline & $14.133 \pm 1.676$ & $12.667 \pm 1.213$ & 0.000 \\
\hline
\end{tabular}

T- Test is applied. $P$ value is significant if $<\mathbf{0 . 0 5}$.

Onset time is the time from the completion of injection of study drug to first loss of pinprick sensation in any of the dermatomes C5-T1.In group R, it was $14.133 \pm 1.676$ min and $12.667 \pm 1.213 \mathrm{~min}$ in group RD. This shows that ropivacaine with dexmedetomidine provides faster sensory block than ropivacaine alone.

\begin{tabular}{|c|c|c|c|}
\hline \multirow{3}{*}{$\begin{array}{l}\text { Onset of motor } \\
\text { block } \\
\text { (In Min) }\end{array}$} & Group R & Group RD & \multirow[b]{2}{*}{ P Value } \\
\hline & Mean \pm SD & Mean $\pm S D$ & \\
\hline & $25.967 \pm 2.748$ & $23.333 \pm 3.467$ & 0.002 \\
\hline
\end{tabular}

\section{T- Test is applied. $P$ value is significant if $<0.05$.}

The total time required to achieve complete paralysis of the upper limb was considered as onset of motor block. In group $\mathrm{R}$, it was $25.967 \pm 2.748 \mathrm{~min}$ and $23.333 \pm 3.467 \mathrm{~min}$ in group RD. $P$ value is 0.002 which is a significant. This shows that ropivacaine with dexmedetomidine provides faster motor block than ropivacaine alone.

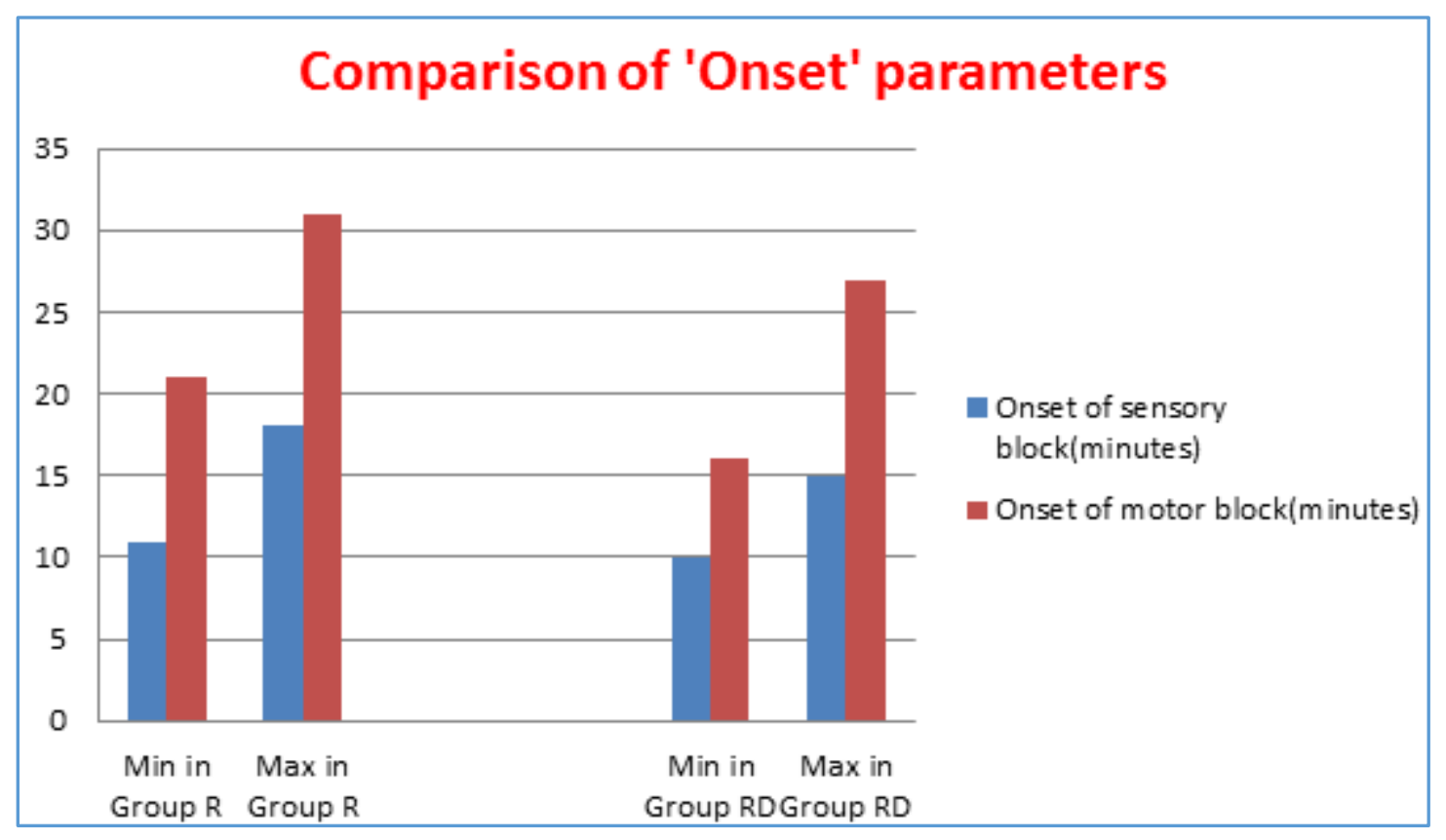

Fig: 1

In present study, the minimum time of onset of sensory block was $10 \mathrm{~min}$ and maximum time was 18 minutes. Minimum time of onset of motor block was $16 \mathrm{~min}$ and maximum time was 31 minutes.

\begin{tabular}{|c|c|c|c|}
\hline \multirow{2}{*}{$\begin{array}{c}\text { Duration of } \\
\text { motor block } \\
\text { (In Min) }\end{array}$} & Group R & Group RD & P \\
\cline { 2 - 3 } & Mean \pm SD & Mean \pm SD & Value \\
\cline { 2 - 3 } & $\begin{array}{c}509.667 \pm \\
24.703\end{array}$ & $\begin{array}{c}760.667 \pm \\
28.062\end{array}$ & 0.000 \\
\hline \multicolumn{3}{|c|}{ Table 3: Comparison of Duration of motor block } \\
\hline
\end{tabular}

$\mathrm{T}$ - Test is applied. $\mathrm{P}$ value is significant if $<0.05$. 
The above mentioned values compare the duration of motor blockade in the two groups. Duration of motor blockade was longer in group RD $(760.667 \pm 28.062 \mathrm{~min})$ compared to group $\mathrm{R}(509.667 \pm 24.703 \mathrm{~min})$ and this difference was statistically significant.

\begin{tabular}{|c|c|c|c|}
\hline $\begin{array}{c}\text { Duration of } \\
\text { sensory } \\
\text { block } \\
\text { (In Min) }\end{array}$ & Group R & Group RD & $\begin{array}{c}\text { P } \\
\text { Mean } \pm \text { SD }\end{array}$ \\
\cline { 2 - 3 } Mean \pm SD & Value \\
\hline \multicolumn{2}{|c|}{ Table 4: Comparison of Duration of Sensory block } \\
\hline
\end{tabular}

T- Test is applied. P value is significant if $<0.05$.
The above mentioned values compare the duration of sensory blockade in the two groups. Duration of sensory blockade was longer in group RD (811.667士25.405min) compared to group

$\mathrm{R}$ (547.833 $\pm 26.152 \mathrm{~min})$ and this difference was statistically significant.

\begin{tabular}{|c|c|c|c|c|}
\hline \multirow{2}{*}{} & \multicolumn{2}{|c|}{ Group R } & \multicolumn{2}{c|}{ Group RD } \\
\cline { 2 - 5 } & Min & Max & Min & Max \\
\hline $\begin{array}{c}\text { Duration of Sensory } \\
\text { block(In Min) }\end{array}$ & 495 & 590 & 765 & 850 \\
\hline $\begin{array}{c}\text { Duration of Motor } \\
\text { block(In Min) }\end{array}$ & 470 & 545 & 720 & 820 \\
\hline \multicolumn{4}{|c|}{ Table 5: Comparison of Total Duration } \\
parameters in two groups \\
\hline
\end{tabular}

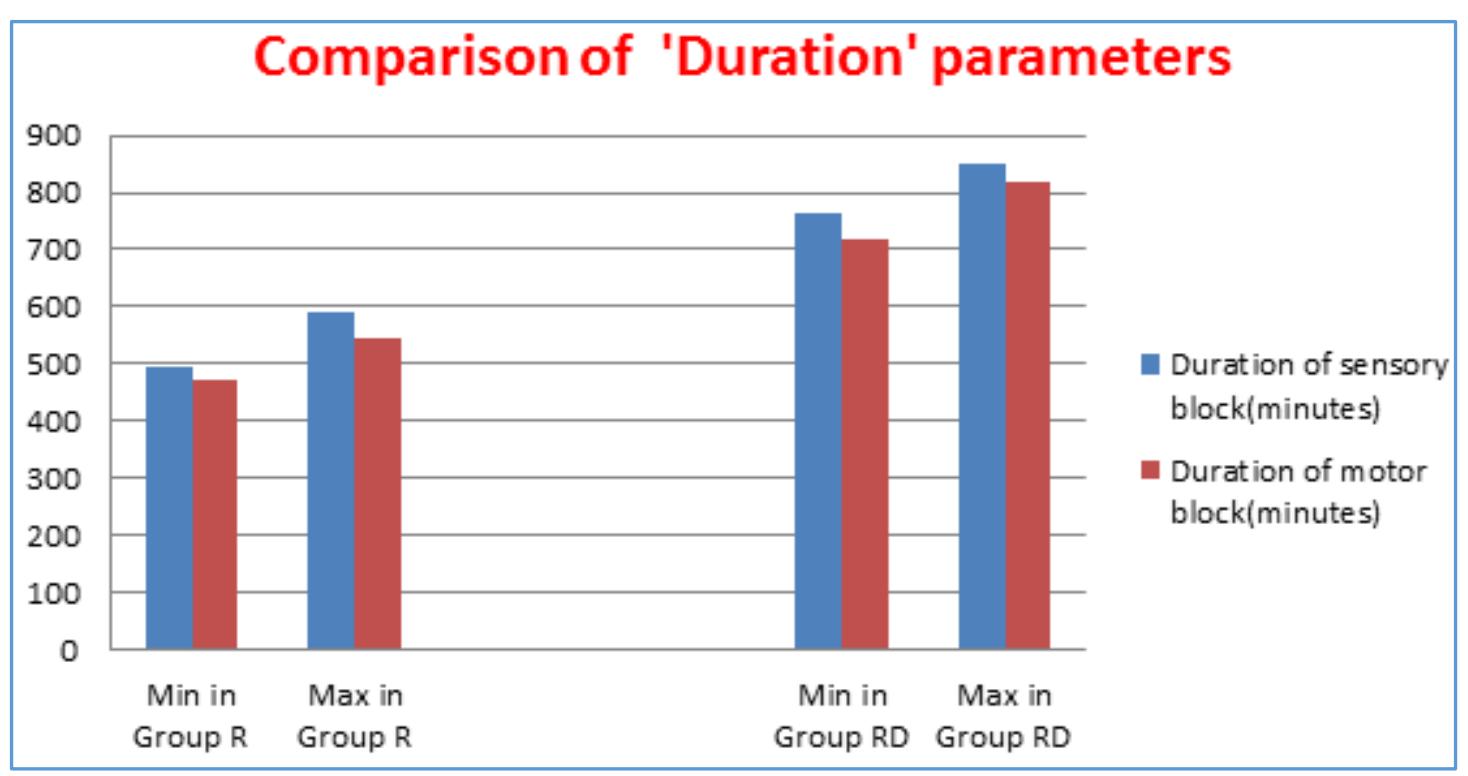

Fig. 2

In present study, the minimum duration of sensory block was $495 \mathrm{~min}$ and maximum time was 850 minutes. Minimum duration of motor block was 470 min and maximum time was 820 minutes.

\section{Haemodynamic Variables}

Haemodynamic parameters (HR, SBP and DBP) were recorded at 0, 5,10,15,20,25,30,45 minutes, $1^{\text {st }} \mathrm{hr}, 2^{\text {nd }} \mathrm{hr}$ and thereafter every second hourly till $24 \mathrm{hrs}$ to record any incidence of bradycardia or hypotension.

ANOVA test was used to compare HR, SBP, and DBP over different intervals of time.

\section{Heart Rate}

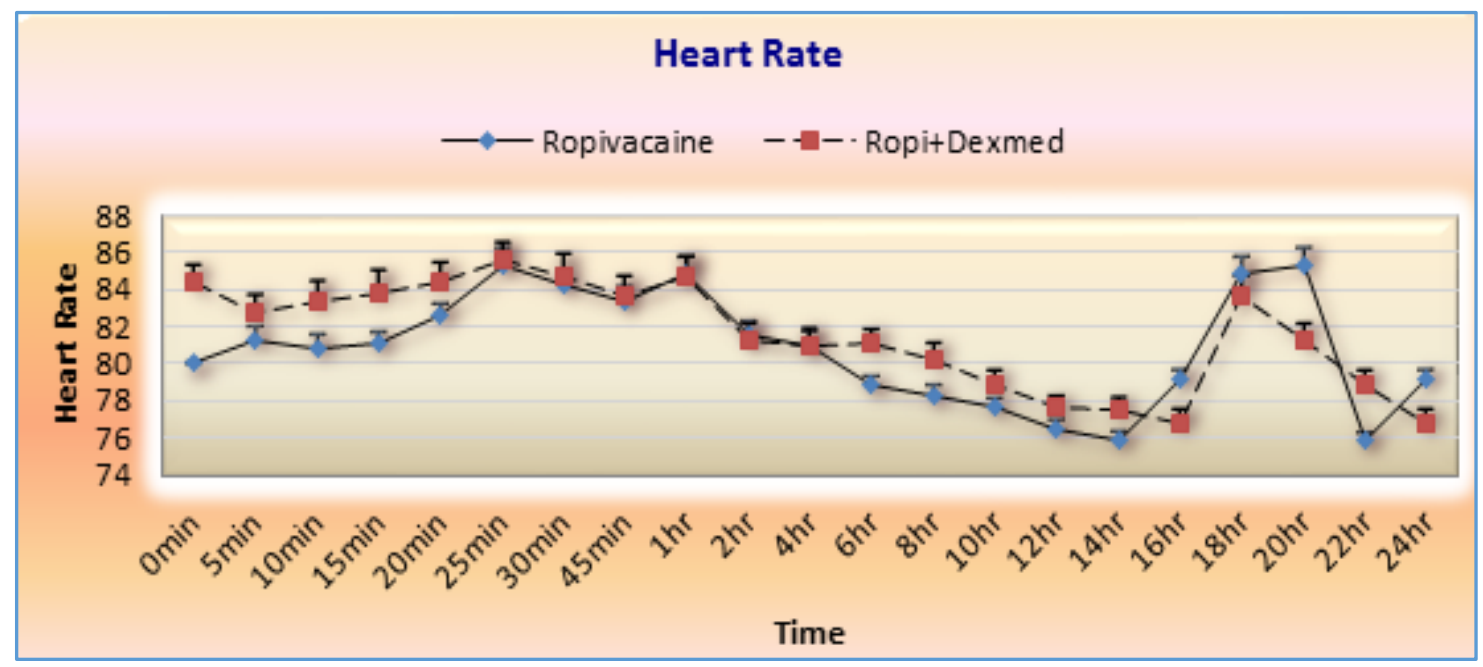

Fig. 3: Heart Rate (min-1) at different time intervals 
- $\quad$ Data displayed on graph are mean values. ANOVA test was applied.

- Heart rate in Group R and Group RD were comparable. The difference was statistically not significant. $(\mathrm{P}=0.476)$

- There was no fall or rise in heart rate more than 15 beats than previous observation.

\section{Blood Pressure}

Systolic Blood Pressure

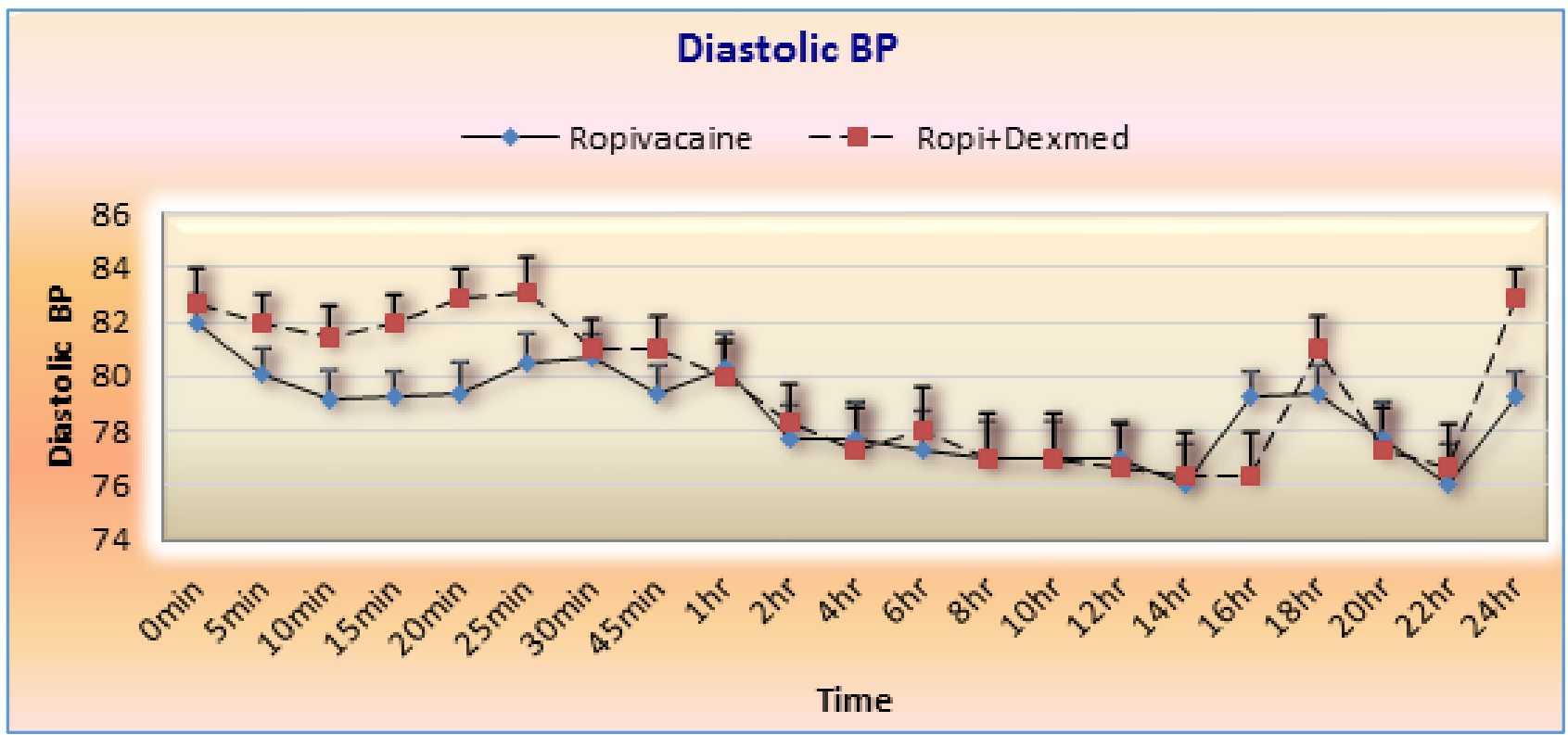

Fig. 4: Systolic Blood Pressure (mmHg) at different intervals

- $\quad$ Data displayed on graph are mean values. ANOVA test was applied.

- $\quad$ SBP in Group R and Group RD were comparable. The difference was statistically not significant $(\mathrm{P}=0.416)$.

\section{Diastolic Blood Pressure}

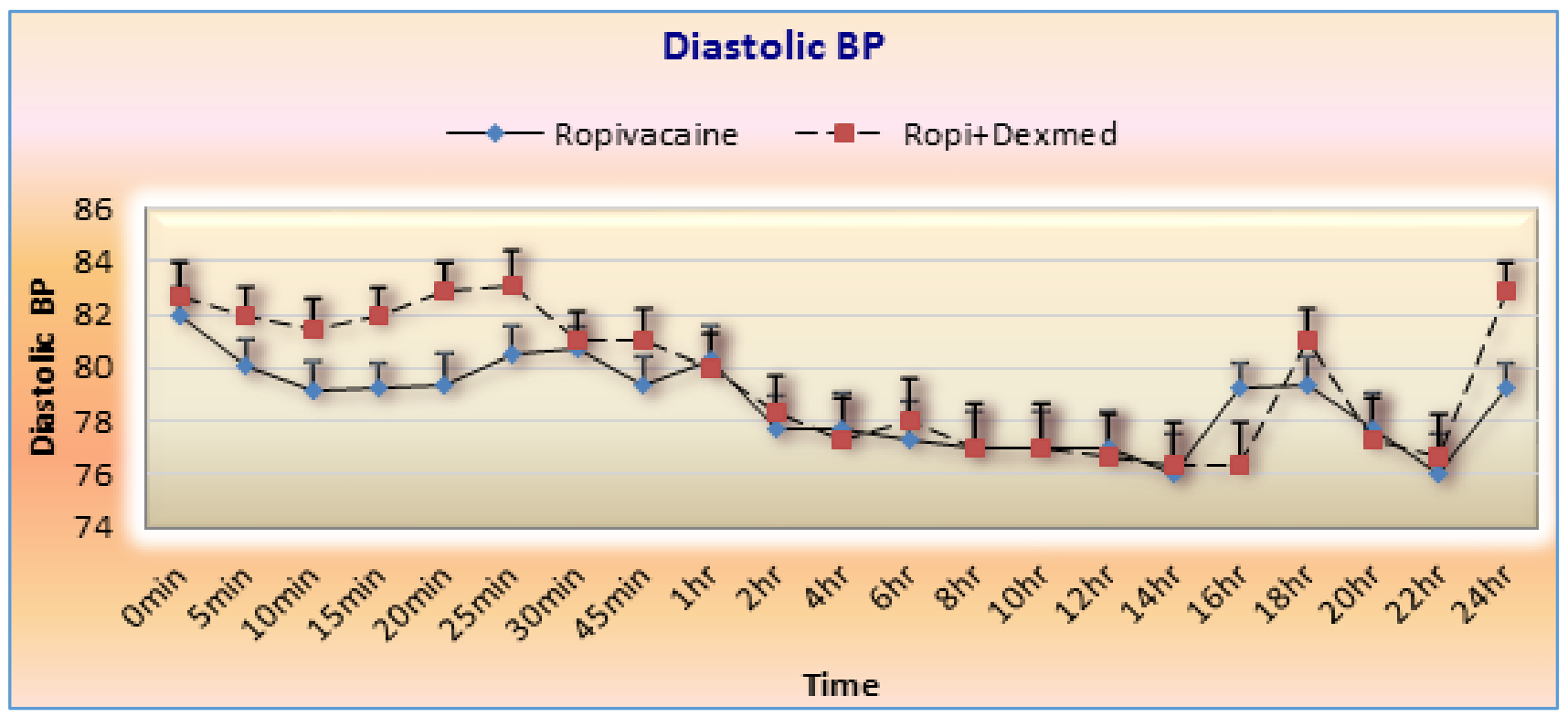

Fig. 5: Diastolic Blood Pressure ( $\mathrm{mmHg}$ ) at different time intervals

- Data displayed on graph are mean values. ANOVA test was applied.

- $\quad$ DBP in Group R and Group RD were comparable. The difference was statistically not significant $(\mathrm{P}=0.784)$.

Thus in the present study we found that there was no significant difference among the two groups in total 24 hours of duration with respect to parameters like HR, SBP and DBP. 


\begin{tabular}{|c|c|c|c|}
\hline \multirow{3}{*}{$\begin{array}{c}\text { Number of } \\
\text { rescue } \\
\text { injections in } 24 \\
\text { hours }\end{array}$} & Group R & Group RD & \multirow[b]{2}{*}{$\begin{array}{c}P \\
\text { Value }\end{array}$} \\
\hline & Mean \pm SD & Mean \pm SD & \\
\hline & $2.733 \pm 0.450$ & $1.400 \pm 0.498$ & 0.000 \\
\hline \multicolumn{4}{|c|}{ quirement of Rescue Analgesia } \\
\hline
\end{tabular}

T- Test is applied. P value is significant if $<0.05$.

In the postoperative period, patients were given IM injection diclofenac $75 \mathrm{mg}$ as rescue analgesic when they started feeling pain and the time and dose of such requirement was recorded. Postoperative VAS scores were recorded up to 24 hours. Total number of rescue injection in this time frame was noted.

The total number of diclofenac doses required in $24 \mathrm{Hrs}$ in Group R was more $(2.733 \pm 0.450)$ as compared to Group RD $(1.400 \pm 0.498)$. The difference was statistically significant $(\mathrm{P}=0.000)$.

Thus, in the present study we found that the requirement of rescue analgesia was more in Group R as compared to Group RD.

\section{Side Effects}

There were no incidences of hypotension, bradycardia, respiratory depression, nausea or vomiting in any of 60 patients of these both study groups. Incidence of pneumothorax, hematoma, accidental intravascular injection, convulsions and neuralgia were nil in either group. Perioperative parameters were also normal in both groups requiring no intervention.

\section{DISCUSSION}

Many drugs have been used as adjuvants to local anesthetic agents to prolong the duration of peripheral nerve blocks. Clonidine, a partial $\alpha-2$ adrenoceptor agonist has been reported to prolong the duration of anesthesia and analgesia during such blocks.

The $\alpha 2: \alpha 1$ selectivity of dexmedetomidine is eight times that of clonidine and its high specificity for $\alpha 2$ subtype makes it a much more effective sedative and analgesic agent. The aim of this study was to evaluate whether additional anesthetic and analgesic effects could be derived from administration of Alpha-2 adrenoceptor agonist Dexmedetomidine into brachial plexus sheath.

Its use in peripheral nerve blocks has recently been described. However, the reports of its use in supraclavicular brachial plexus block are limited. In this study, we investigated whether adding dexmedetomidine to ropivacaine for supraclavicular brachial plexus block would affect the sensory and motor blocks and duration of analgesia.

The present study "Comparative study of ropivacaine alone versus ropivacaine with dexmedetomidine in supraclavicular brachial plexus block" was carried out on patients undergoing elective upper limb surgery at ACSR GMC, Nellore, in the Department of Anaesthesiology during the period from August 2015 to November 2015. The study was carried out to compare hemodynamic, sedative, motor and sensory effects of Ropivacaine alone and Ropivacaine along with Dexmedetomidine in supraclavicular brachial block in upper limb surgery.

\section{Drugs selected for the study}

In our study, the drugs selected for brachial plexus block were Ropivacaine and Dexmedetomidine. There have been a few clinical studies evaluating the effect of mixing dexmedetomidine with local anesthetics during placement of peripheral nerve blockade. Peripheral analgesic effects of dexmedetomidine have enabled an overall improved blockade quality when added to local anesthetics in a peripheral nerve block model and are thought to be mediated by $\alpha 2$-receptor binding. In a randomized double-blind trial performed by Esmaoglu et al. ${ }^{4}$ dexmedetomidine added to levobupivacaine for axillary brachial plexus blockade shortened the block onset time, prolonged the duration of motor and sensory effects and extended postoperative analgesia. In addition, dexmedetomidine mixed with lidocaine has been reported to decrease tourniquet pain, improve block quality and prolonged postoperative analgesia during intravenous regional anesthesia.

The duration of analgesia, when only local anesthetic is used is very short and does not extend into post-operative period for more than 3-4 hours. Various drugs have been tried as adjuvant to local anesthetics for prolonging the analgesia and improving the quality of block. Hence, we selected dexmedetomidine as an adjuvant to Ropivacaine in our study. Bupivacaine is being regularly used for brachial plexus block for upper limb orthopedics surgeries in most of the hospitals. Ropivacaine, another local anaesthetic with structural similarity to bupivacaine without its cardio toxic effects has been introduced to Indian market already. Ropivacaine has been found to be equally effective as bupivacaine for brachial plexus block by various authors. 5,6

Hence, Ropivacaine was selected as local anaesthetic for our study.

In our study we used only 25 microgram dexmedetomidine as adjunct to ropivacaine, because there are more chances to have bradycardia and hypotension with higher doses of dexmedetomidine.

\section{Onset of Sensory Block}

In our study, we observed that onset time was $14.133 \pm 1.676$ min in group $\mathrm{R}$ and $12.667 \pm 1.213 \mathrm{~min}$ in group RD. (P value $<0.05$ ) Here onset time is the time from the completion of injection of study drug to loss of pinprick sensation.

This observation well matches with study of Sandhya Agarwal. ${ }^{3}$ onset of sensory $13.20 \pm 1.848 \mathrm{~min}$ and $19.04 \pm 3.195$ min in dexmedetomidine group and control group respectively.

Similar observation was made by Aliye Esmaoglu. ${ }^{4}$ where the onset time of sensory block was much faster in dexmedetomidine group, $9.03 \pm 1.15$ min compared to that of placebo (10.46 $\pm 1.30 \mathrm{~min})$.

This shows that ropivacaine with dexmedetomidine provides faster sensory block than ropivacaine alone.

\section{Onset of Motor Block}

In our study, we observed that onset of motor block was earlier in study group of dexmedetomidine having the mean value of $23.333 \pm 3.467 \mathrm{~min}$ and in comparison, the control group had a mean value of $25.967 \pm 2.748 \mathrm{~min}$ which is statistically significant ( $p=0.002)$. 
This observation matches well with the study conducted by Sandhya Agarwal. ${ }^{3}$ who had earlier onset of motor blockade in dexmedetomidine group compared to control group, $16.3 \pm 1.7 \mathrm{~min}$ and $22.7 \pm 2.8 \mathrm{~min}$ respectively. Similar observation was made by Aliye Esmaoglu. ${ }^{4}$ where the onset time of motor block was much faster in dexmedetomidine group compared to that of placebo.

\section{Duration of Motor Block}

The duration of motor block, in our study was $760.667 \pm 28.062$ min with dexmedetomidine group-RD and $509.667 \pm 24.703 \mathrm{~min}$ for control group- $R$, which is statistically significant $(\mathrm{p}=0.000)$.

This observation matches well with the study conducted by Rachana Gandhi. ${ }^{2}$ who had longer duration of motor blockade in dexmedetomidine group compared to control group, $660.2 \pm 60.4 \mathrm{~min}$ and $100.7 \pm 48.3 \mathrm{~min}$ respectively.

Similar observation was made by Aliye Esmaoglu. ${ }^{4}$ where the duration of motor block was much longer in dexmedetomidine group-RD773.00 $\pm 67.62 \mathrm{~min}$ compared to that of placebo group-R $(575.00 \pm 65.00 \mathrm{~min})$.

This observation also well matches with study of Sandhya Agarwal. ${ }^{3}$ duration of motor block 702.0 \pm 111.6 min and $208.0 \pm 22.7 \mathrm{~min}$ in dexmedetomidine group-RD and control group-R respectively.

This shows that dexmedetomidine also prolongs total duration of motor block if added to local anaesthetics.

\section{Duration of Sensory Block/Duration of Analgesia}

In our study duration of sensory blockade is the time from the onset of sensory blockade to till the patients complain of pain at the site of surgery and rescue analgesia was given. So it is also considered as "duration of analgesia" in our study.

The duration of sensory blockade, in our study was $811.667 \pm 25.405$ min with dexmedetomidine group-RD and $547.833 \pm 26.152 \mathrm{~min}$ for control group $-\mathrm{R}$, which is statistically significant $(\mathrm{p}=0.000)$.

Aliye Esmaoglu. ${ }^{4}$ in his study, found that the duration of sensory block was longer in dexmedetomidine group compared with placebo $887 \pm 66.23$ min versus $673.00 \pm 73.77 \mathrm{~min}$. These observation were similar to our study. In a study conducted by Rachana Gandhi. ${ }^{2}$ the duration sensory block was $732.4 \pm 48.9 \mathrm{~min}$ in the dexmedetomidine group, compared with $146.5 \pm 36.4 \mathrm{~min}$ in the control group.

This shows that dexmedetomidine prolongs sensory block of supraclavicular brachial plexus block very significantly.

\section{Ramsay Sedation Scale Score}

Sedation in our study was assessed by Ramsay sedation scale. Patients from both the study groups were not sedated at any specific time during 24 hours. Their sedation score were either 1 or 2 . The mean Ramsay sedation scores of Group R was almost equal to Group RD.

This shows that dexmedetomidine at low doses if used in supraclavicular block will not produce any sedation in patients.

\section{Total requirement of rescue analgesia in $\mathbf{2 4}$ hours}

As we have already seen that dexmedetomidine prolongs total duration of sensory block means it extends total duration of analgesia too. Because of this, patient may require less number of rescue analgesic injection in postoperative period. In our study we found that total number of rescue analgesic injections in 24 hours were higher in group-R $(2.733 \pm 0.450)$ than in group-RD $(1.400 \pm 0.498)$.

\section{Haemodynamic Variables}

In our study hemodynamic parameters (HR, SBP and DBP) were recorded at $0,5,10,15,20,25,30,45$ minutes, $1^{\text {st }} \mathrm{hr}, 2^{\text {nd }} \mathrm{hr}$ and thereafter every second hourly till $24 \mathrm{hrs}$.

There was no any incidence of fall in blood pressure more than $20 \mathrm{mmHg}$ in comparison to baseline reading. No patient had bradycardia or tachycardia.

This shows that dexmedetomidine did not had side effects like bradycardia and hypotension if it is used in small doses (Less than 30 microgram) as an adjuvant with local anesthetics in supraclavicular brachial plexus block.

The results in our study showed that dexmedetomidine $25 \mu \mathrm{g}$ can be used safely as an adjuvant to Ropivacaine to prolong the duration of sensory blockade /analgesia.

\section{SUMMARY}

\section{RESULTS:}

There was no significant difference in the study groups with regards to demographic profile and duration of surgery. The onset of sensory and motor blockade was faster in group-RD than group-R. \{Onset of sensory block: (group- $\mathrm{R}=$ $14.133 \pm 1.676 \mathrm{~min} \&$ group $-\mathrm{RD}=12.667 \pm 1.213 \mathrm{~min})(\mathrm{p}=0.000)$, Onset of motor block: (Group-R $=25.967 \pm 2.748 \mathrm{~min} \&$ group$\mathrm{RD}=23.333 \pm 3.467 \mathrm{~min})(\mathrm{p}=0.002)\}$

Also total duration of sensory blockade \{Group $\mathrm{R}=547.833 \pm 26.152$ mins, Group $\mathrm{RD}=811.667 \pm 25.405$ mins ( $\mathrm{p}$ value $=0.000)$ \}, motor blockade \{Group $\mathrm{R}=509.667 \pm 24.703$ mins, Group $\mathrm{RD}=760.667 \pm 28.062$ mins (p value $=0.000)\}$ and number of rescue injections in 24 hours \{Group $\mathrm{R}=2.733 \pm 0.450$, Group $\mathrm{RD}=1.400 \pm 0.498$ ( $\mathrm{p}$ value $=$ $0.000)\}$ was significantly different in two groups. There was good haemodynamic stability in both groups. There was no incidence of any side effects in both groups. There was no incidence of hypotension and bradycardia in any of the sixty patients.

\section{CONCLUSION}

Dexmedetomidine in a dose of $25 \mu$ g added to ropivacaine in supraclavicular brachial block for upper limb surgery significantly shortens the onset time and prolongs the duration of sensory and motor blocks without producing sedation in patients. Total number of rescue analgesics required in postoperative period is also less with use of Dexmedetomidine as an adjuvant to Ropivacaine.

\section{REFERENCES}

1. Hickey R, Hoffman JRN, Ramamurthy MSNS. A comparison of Ropivacaine 0.5\% and Bupivacaine 0.5\% for Brachial plexus block. Anaesthesiology 1991;74:63942.

2. Gandhi R, Shah A, Patel I. Use of dexmedetomidine along with bupivacaine for brachial plexus block.NJMR2012 ;2(1):67-69.

3. Agarwal S, Aggarwal R, Gupta P. Dexmedetomidine prolongs the effect of bupivacaine in supraclavicular brachial plexus block. J Anaesthesiol Clinical Pharmacol 2014;30:36-40. 
4. Esmaoglu A, Yegenoglu F, Akin A, Yildirim C. Dexmedetomidine added to Levobupivacaine prolongs axillary brachial plexus block. Anesth Analg 2010;111:1548-51.

5. Vaghadia H, Chan V, Ganapathy S, Lui A, McKenna J, Zimmer K. A multicentre trial of Ropivacaine $7.5 \mathrm{mg} / \mathrm{ml}$ v/s Bupivacaine $5 \mathrm{mg} / \mathrm{ml}$ for supraclavicular brachial plexus anaesthesia. Can J Anaesth 1999;46(10):946-51.
6. Piangatelli C, DeAngelis C, Pecora L, Recanatini F, Cerchiara P, Testasecea D. Ropivacaine and levobupivacaine in the infraclavicular brachial plexus block. Minerva Anaesthesiol 2006;72:217-21. 